\title{
Uncertainties in climate responses to past land cover change: First results from the LUCID intercomparison study
}

\author{
A. J. Pitman, ${ }^{1}$ N. de Noblet-Ducoudré, ${ }^{2}$ F. T. Cruz, ${ }^{1}$ E. L. Davin, ${ }^{2,3}$ G. B. Bonan, ${ }^{4}$ \\ V. Brovkin, ${ }^{5}$ M. Claussen, ${ }^{5}$ C. Delire ${ }^{6}$ L. Ganzeveld, ${ }^{7}$ V. Gayler, ${ }^{5}$ B. J. J. M. van den Hurk, ${ }^{8}$ \\ P. J. Lawrence, ${ }^{4}$ M. K. van der Molen, ${ }^{8,9}$ C. Müller, ${ }^{10,11}$ C. H. Reick, ${ }^{5}$ S. I. Seneviratne, ${ }^{3}$ \\ B. J. Strengers, ${ }^{11}$ and A. Voldoire ${ }^{6}$
}

Received 6 May 2009; accepted 10 June 2009; published 23 July 2009.

[1] Seven climate models were used to explore the biogeophysical impacts of human-induced land cover change (LCC) at regional and global scales. The imposed LCC led to statistically significant decreases in the northern hemisphere summer latent heat flux in three models, and increases in three models. Five models simulated statistically significant cooling in summer in near-surface temperature over regions of LCC and one simulated warming. There were few significant changes in precipitation. Our results show no common remote impacts of LCC. The lack of consistency among the seven models was due to: 1) the implementation of LCC despite agreed maps of agricultural land, 2) the representation of crop phenology, 3) the parameterisation of albedo, and 4) the representation of evapotranspiration for different land cover types. This study highlights a dilemma: LCC is regionally significant, but it is not feasible to impose a common LCC across multiple models for the next IPCC assessment. Citation: Pitman, A. J., et al. (2009), Uncertainties in climate responses to past land cover change: First results from the LUCID intercomparison study, Geophys. Res. Lett., 36, L14814, doi:10.1029/2009GL039076.

\section{Introduction}

[2] Land cover change (LCC, removal of forests and natural grass land for crops or grazing, replacement of crops and grasses by forests, etc.) affects regional climate through impacts on the surface albedo and radiative forcing [Forster et al., 2007], partitioning of available energy between sensible and latent heat, boundary layer temperature, mois-

\footnotetext{
${ }^{1}$ Climate Change Research Centre, University of New South Wales, Sydney, New South Wales, Australia.

${ }^{2}$ Laboratoire des Sciences du Climat et de l'Environnement, UVSQ, CEA, CNRS, Gif-sur-Yvette, France.

${ }^{3}$ Institute for Atmospheric and Climate Science, ETH Zürich, Zurich, Switzerland.

${ }^{4}$ National Center for Atmospheric Research, Boulder, Colorado, USA.

${ }^{5}$ Max Planck Institute for Meteorology, Hamburg, Germany.

${ }^{6}$ Groupe d'étude de l'Atmosphère Météorologique, Météo-France, CNRS, Toulouse, France.

${ }^{7}$ Department of Environmental Sciences, Wageningen University and Research Centre, Wageningen, Netherlands.

${ }^{8}$ Netherlands Royal Meteorological Institute, De Bilt, Netherlands.

${ }^{9}$ Faculty of Earth and Life Sciences, VU University Amsterdam, Amsterdam, Netherlands.

${ }^{10}$ Potsdam Institute for Climate Impact Research, Potsdam, Germany.

${ }^{11}$ Netherlands Environmental Assessment Agency, Bilthoven, Netherlands.
}

Copyright 2009 by the American Geophysical Union. 0094-8276/09/2009GL039076 ture profile and depth, and the partitioning of rainfall between evaporation and runoff [Pitman, 2003]. LCC also affects the emissions and deposition of carbon, nitrogen and other chemically active species that may have a global-scale impact on climate and ecosystem functioning inducing potentially relevant feedback mechanisms. The global and regional climate modelling communities have demonstrated impacts on surface temperature, rainfall, and turbulent energy fluxes if land cover is perturbed [Henderson-Sellers et al., 1993; Chase et al., 2000; Werth and Avissar, 2002; Findell et al., 2006]. This is consistent with the strong impact of land surface processes on the atmosphere in some regions [Koster et al., 2004; Seneviratne et al., 2006]. Findell et al. [2009] note that over areas of LCC the impact on the regional hydrometeorology can be comparable with climate anomalies such as the El Niño-Southern Oscillation. As global climate model projections are used to explore the impacts of climate change on regions that have undergone intensive LCC, the need to include this forcing seems indisputable.

[3] Converting forests to pasture and crops commonly decreases radiative forcing via an increase in albedo which tends to cool the global climate via the radiation balance [Davin et al., 2007]. Changes in albedo can be amplified via a positive feedback with snow [Betts, 2000; Claussen et al., 2001]. These biogeophysical feedbacks are compensated for at the global scale by warming due to changes in atmospheric $\mathrm{CO}_{2}$ caused by changes in terrestrial carbon stocks [e.g., Claussen et al., 2001]. Here, we focus on the biogeophysical effects and do not include changes in carbon.

[4] LCC is the dominant anthropogenic forcing of climate in the pre-industrial period. Regionally LCC induces a cooling or warming depending on (a) the duration of the growing season, (b) changes in albedo and (c) how the partitioning of available energy between sensible and latent heat flux, caused by changes in roughness length, root depth, stomatal conductance etc, interacts with the atmosphere and clouds [Findell et al., 2007]. While large-scale LCC strongly affects the regional climate over cleared areas there is no agreement on the impact of the biogeophysical changes induced by LCC on areas remote from the perturbation. Teleconnections, where LCC in one region is used to explain changes over another, have been addressed many times. Some authors find clear teleconnections [e.g., Gedney and Valdes, 2000], while others do not [e.g., Findell et al., 2007]. Clarifying this issue is important since significant teleconnections would imply a regional and a global scale response from LCC.

[5] The project "Land-Use and Climate, IDentification of robust impacts" (LUCID) was conceived under the auspices of IGBP-iLEAPS and GEWEX-GLASS, to address the 


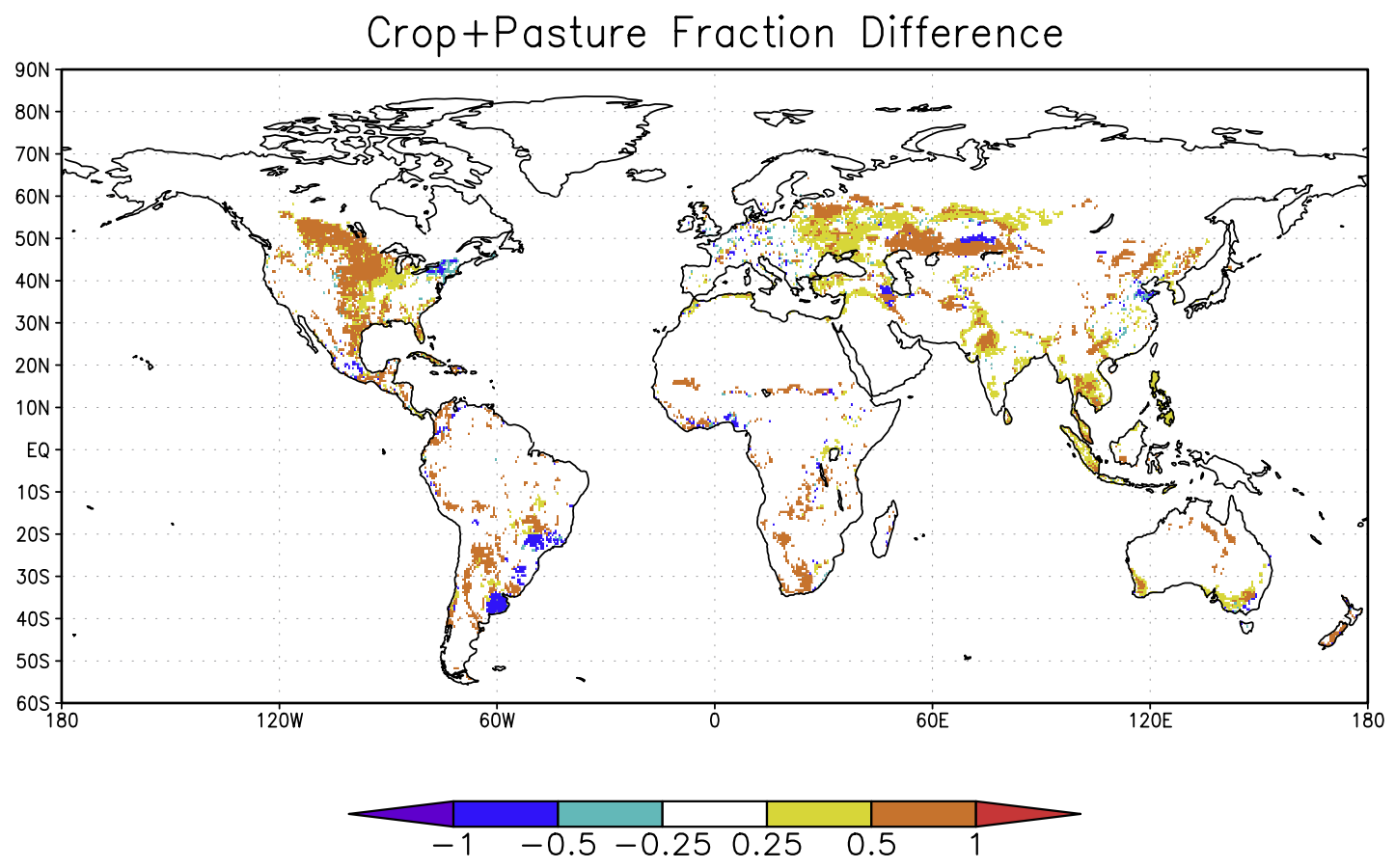

Figure 1. Extent of land cover change between experiments PD and PDv (PD - PDv) expressed as the difference in crop and pasture cover between the two experiments. Blue colours represent changes that decrease pasture and crop cover while yellows and browns are increases $(25 \%-50 \%$ and $50-100 \%$ respectively).

robustness of possible (remote) impacts of LCC. LUCID explores those impacts of LCC that are robust - that is, above the noise generated by model variability and consistent across multiple climate models. We provide here the key results from LUCID: are there robust regional-scale impacts of LCC across seven climate models when land cover is perturbed using common crop and pasture change maps? Do these trigger remote changes to climate that are common to multiple models?

\section{Methodology}

[6] Two experiments were conducted using prescribed interannually and seasonally varying SST and sea ice extent using data from the C20C project (HadISST1.1, ftp://www. iges.org/pub/kinter/c20c/HadISST/):

[7] 1. Present-day simulations, with all greenhouse gases, land cover and sea surface temperatures (SSTs) prescribed at their present-day values. The land cover is prescribed using a map reflecting 1992 and the period 1972-2002 is simulated. Five independent realizations were run by each group (experiment PD).

[8] 2. As PD but with a land cover map reflecting 1870 conditions (experiment PDv).

[9] The change in global vegetation patterns due to LCC is shown in Figure 1. The land cover maps used crop area constructed by Ramankutty and Foley [1999] combined with pasture area from Goldewijk [2001], both provided at $0.5^{\circ} \times 0.5^{\circ}$. Each modelling group implemented the fractions onto their existing natural land cover distributions using somewhat different strategies (Text S1 of the auxiliary material). ${ }^{1}$ The use of a common natural vegetation map

\footnotetext{
${ }^{1}$ Auxiliary materials are available in the HTML. doi:10.1029/ 2009GL039076.
}

was not feasible since this map (if one could be agreed), the associated parameters and the land surface models (LSMs) are developed together. Replacing the natural land cover distribution would have led to a significant recalibration of land surface parameters with potential impacts on the atmospheric model requiring re-testing and re-optimization of each model. This process can take several years and is undoable within the time frame of the AR5. There is also a lack of knowledge of how to prescribe LCC correctly, including what happened to abandoned crops (e.g., natural re-growth, tree plantation). These issues led to differences in the implementation of the 1870 and 1992 crop and pasture maps by each group despite the perturbation to land cover being prescribed. Land cover maps are used in different ways by the LSMs in the climate models. Some LSMs compute a daily leaf area index (LAI) while others prescribe LAI from observations and omit feedbacks from the seasonal adaptation of vegetation to the modelled climate (Text S1). Fundamentally, decisions by each modeller results in important differences in how parameters that affect the atmospheric model (e.g., surface albedo, land surface roughness, etc.) are changed. This is inevitable: a common LCC impact would require everyone to use the same LSM, coupled to the atmosphere via a common boundary layer scheme linked to a common convection and cloud scheme. This would then fail to address the need to use multiple models to assess the impact of LCC and preclude the use of LCC in IPCC assessments that require a multi-model approach. Details of the climate models used are provided in Text S2. Details of the LSMs, including evaluation protocols are given in Text S3. An assessment of the scale of LCC is provided in Table S1.

[10] We follow Findell et al. [2007] in using the modified Student's $t$-test [Zwiers and von Storch, 1995] to compare 
differences between results at each model grid cell. This test is more rigorous than the standard $t$-test because it accounts for autocorrelation within the time series, reducing the rate of false positives.

\section{Results}

[11] We highlight a small sample of results: the impact of LCC on mean June-July-August (JJA) latent heat flux (LHF), near-surface temperature, and precipitation. We only show results that are statistically significant at a 95\% level. Results were generally similar in terms of significance for northern hemisphere spring.

[12] LCC affects the LHF in complex ways [Bonan, 2008]. Replacing forests with crops or pasture decreases roughness length, root depth, LAI etc. and increases albedo. These tend to reduce the efficiency of transpiration and canopy evaporation although reduced canopy cover can increase soil evaporation. The net change in total evaporation due to LCC is therefore uncertain and depends on: complex interactions between these components and the atmosphere; exactly how each type of vegetation is parameterized in each model; and how strongly the land is coupled to the atmosphere.

[13] Figure 2 (left) shows an impact of LCC on the LHF over regions of LCC (mainly deforestation). IPSL, CCAM, and SPEEDY show decreases $\left(10-20 \mathrm{~W} \mathrm{~m}^{-2}\right)$ in the LHF over Europe and eastern US. ARPEGE simulates mixed changes over Europe and decreased LHF over eastern US. ECHAM5, ECEarth and CCSM show increases over Europe and parts of the eastern US $\left(5-10 \mathrm{~W} \mathrm{~m}^{-2}\right)$. Figure 3 shows that IPSL, SPEEDY, ECHAM5, CCAM and CCSM simulated statistically significant changes in the LHF over 36$63 \%$ of the grid points with LCC. All models show remote changes below the $5 \%$ of area expected by chance.

[14] Figure 2 (middle) shows the changes in JJA temperature. Five of the seven models simulate cooling over regions of LCC. All models simulate significant temperature changes over $17-49 \%$ of areas of LCC, but no model simulates changes remote from the regions of LCC that approach statistical significance (Figure 3). At the annual timescale results are also inconsistent with cooling in the northern lands (Figure S1) varying from local and negligible to large and widespread.

[15] Rainfall changes are smaller, more randomly distributed and almost always within $\pm 0.1 \mathrm{~mm} \mathrm{~d}^{-1}$ (Figure 2, right) or are not statistically significant. However, Figure 3 shows some models still simulate statistically significant changes (usually reductions) over more perturbed grid points than would be expected by chance (IPSL, SPEEDY, ECHAM5, CCAM). Exploration of whether this high sensitivity in rainfall is related to coupling strength [Koster et al., 2004] will be conducted in the future.

\section{Discussion and Implications for AR5}

[16] Results from every climate model show a clear and statistically significant impact of LCC on the simulated LHF and near-surface temperature over the regions of LCC (Figure 3). However, the direction of regional change differs. Three of the seven models simulate a decrease in the LHF (Figure 2, left) due to lower net radiation and a reduced capacity to transfer water from the root zone to the atmosphere. Five of the seven models simulate a decrease in JJA temperature (Figure 2, middle) since the lower latent heat flux (that should cause warming) is more than offset by a higher albedo and less net radiation. On annual timescales all models simulate cooling over regions of LCC in the northern hemisphere (Figure S1) ranging from negligible (ECHAM5, CCAM, CCSM, IPSL) to very large $\left(>1{ }^{\circ} \mathrm{C}\right)$ (SPEEDY, ECEarth, ARPEGE). Our results capture key uncertainties in how LCC affects the atmosphere [Bonan, 2008]. In all LUCID models, LCC reduces net radiation due to an albedo increase, but this does not always reduce LHF. The response of the LHF to LCC is unclear (particularly in temperate latitudes) because the mechanisms that balance the evaporative response with the net radiation change differ between models.

[17] IPSL simulates a decrease in LHF and an increase in JJA temperature (Figure 2, middle) due to a change in the seasonal cycle of vegetation when trees and natural grasslands are replaced by crops. The earlier onset of leaves in the case of crops is followed by earlier senescence and therefore more unshaded ground in the PD simulation than in PDv during summer. In contrast to the other models, the impact of the larger albedo on surface temperature is largely offset by reduced evaporation. In ECHAM5 the later onset of crop leafing increases soil water availability in summer so that (opposite to IPSL) LHF is increased. Evaporative cooling adds to the temperature decrease from increased albedo. This highlights the fundamental challenge in LCC experiments, and implementing LCC scenarios in IPCC AR5. While expansion of agriculture typically increases surface albedo and reduces roughness length, the implementation of the pasture and crop fractions onto the natural vegetation maps critically depends on:

[18] 1. The diversity in implementation of LCC between individual models (Text S1). Most reduced vegetation proportionally, but then it matters how much of each type is present at pre-industrial times within a grid square. If the main vegetation type is grass, changing this to crops has a very different impact to removal of trees, in part due to links to the snow albedo feedback on seasonal scales [Betts, 2000]. One model implemented crops and pasture by removing the dominant vegetation type (say trees) to reflect forest clearance for agriculture.

[19] 2. The representation of crop phenology in LSMs. This modifies the intensity and the efficiency of the fluxes exchanged between the land and the atmosphere. Some LSMs prescribe phenology using present-day satellite-derived datasets, others simulate seasonal phenology with implicit or calculated dates for cropping and harvest, others simply describe crops as natural grassland but with a different set of parameter values, without representing harvesting (Text S1). Some LSMs only represent natural vegetation and describe pasture and crops as a single type of grass. Some simulate bare soil between harvest and sowing, others simulate grass.

[20] Ultimately, the expression of LCC in a climate model depends on how vegetation types are parameterized, how the LSM tiles the surface (there are several approaches), how land covers are actually implemented, which parameters are fixed, which are time-varying, how these differ between LSMs and how strongly the surface is coupled to the atmosphere [Seneviratne et al., 2006]. A common land-cover 

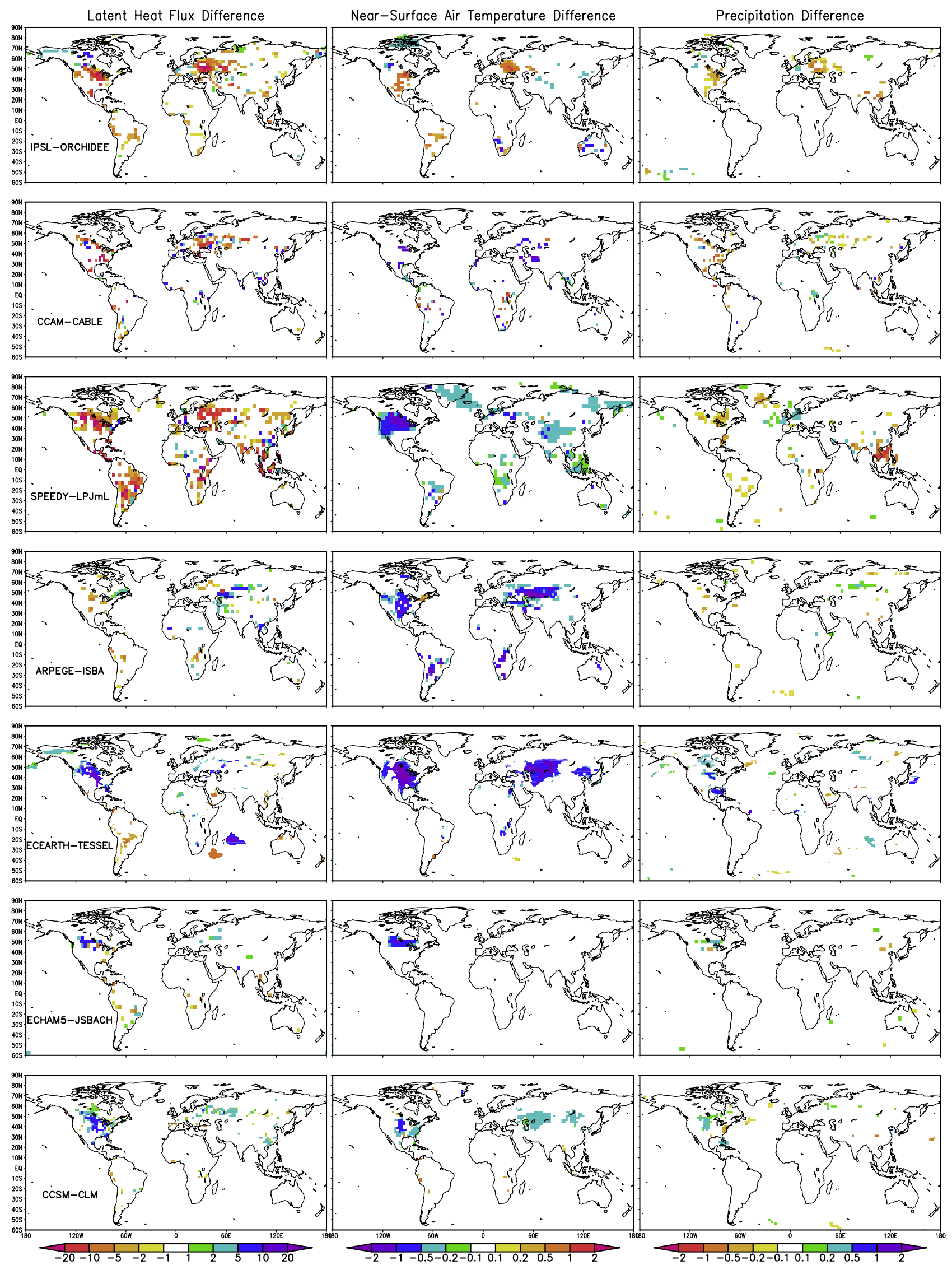

Figure 2. Change in the JJA (left) latent heat flux $\left(\mathrm{W} \mathrm{m}^{-2}\right)$, (middle) near-surface air temperature $\left({ }^{\circ} \mathrm{C}\right)$ and (right) precipitation $\left(\mathrm{mm} \mathrm{d}^{-1}\right)$ from each model resulting from the land cover change (PD - PDv). Only areas where changes are significant at a $95 \%$ confidence using the modified t-test are shown. 


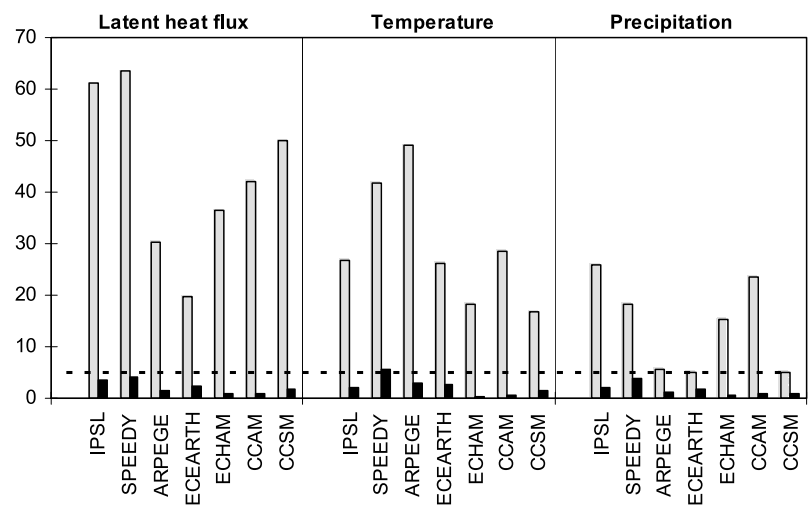

Figure 3. Percent of land area that exhibits statistically significant changes in JJA latent heat flux, temperature and precipitation. Light gray bar is the percent of grid points with statistically significant changes where land cover changes (change in LAI $>0.5$ ) within each climate model. The solid bar is the percent of grid points with statistically significant changes where land cover is not changed. The horizontal line is the $5 \%$ significance level, expected by

map is therefore impossible to impose to all models in this context. Further, a common set of procedures by which a common LCC perturbation can be imposed on multiple climate models is unlikely to be possible. LUCID demonstrates that a multi-model approach is essential to assess the impact of LCC on regional and global climate. The anticipated increase in the spread of regional climate projections from coupled climate models due to the inclusion of LCC reflects the uncertainty associated with many aspects of land processes. Our results also have an important implication for the use of climate models in detection and attribution studies. Failure to account for LCC in regions of intense modification either means the climate model will fail to capture observed trends, or it captures the observed trends for the wrong physical reasons. Disagreement between the IPSL and the ECHAM5 models suggest that proper crop phenology (and perhaps irrigation) is required to capture regional changes through the 20th century in some regions.

\section{Conclusions}

[21] In conclusion, LUCID results suggest that the statistically significant impacts of past LCC are restricted to regions of LCC (Figure 3). Four of the models simulate cooling of $2^{\circ} \mathrm{C}$ over eastern US and three simulate cooling of $0.5^{\circ} \mathrm{C}$ over Europe. Findell et al. [2009] noted that changes of this magnitude were comparable to large ocean SST anomalies. Thus, the IPCC 5th Assessment Report (AR5) should implement LCC since it is regionally significant, recognizing it will cause divergence over regions of LCC in the models. LUCID did not identify any region, remote from LCC, where there are impacts that approach statistical significance or where several models agree on a remote teleconnection pattern. While we only show JJA, this is true for all seasons.

[22] We recognise several limitations in our results. First, fixed SSTs may damp global-scale teleconnections resulting from LCC if they exist. LUCID plans fully-coupled experiments in the future. Second, we note that others have found teleconnections with fixed SSTs; we suggest that by using multiple realizations and the modified t-test to exclude changes that are caused by model variability and by using multiple models our results are more robust than earlier studies that used a single model. Third, we imposed small LCCs in the tropics and it is arguably more likely that global scale teleconnections would be triggered from this region [Werth and Avissar, 2002]. Clearly, including future LCC in climate projections [Feddema et al., 2005] is necessary but is not possible to implement in a common way for AR5. Finally, our simulations only included the biogeophysical effects of LCC on climate. Additional impacts may have occurred had we included changes in land-atmosphere exchange of greenhouse gases, reactive trace gases and aerosols as a function of LCC.

[23] Acknowledgments. This project was launched under the auspices of IGBP-iLEAPS and GEWEX-GLASS. Part of this work was sponsored by the French National Agency for Research (project DIVA/ANR-05-BLAN0167).

\section{References}

Betts, R. A. (2000), Offset of the potential carbon sink from boreal forestation by decreases in surface albedo, Nature, 408, 187-190, doi:10.1038/ 35041545.

Bonan, G. B. (2008), Forests and climate change: Forcings, feedbacks, and the climate benefits of forests, Science, 320, 1444-1449, doi:10.1126/ science. 1155121 .

Chase, T. N., R. A. Pielke Sr., T. G. F. Kittel, R. R. Nemani, and S. W. Running (2000), Simulated impacts of historical land cover changes on global climate in northern winter, Clim. Dyn., 16, 93-105, doi:10.1007/ s003820050007.

Claussen, M., V. Brovkin, and A. Ganopolski (2001), Biogeophysical versus biogeochemical feedbacks of large-scale land-cover change, Geophys. Res. Lett., 28, 1011-1014, doi:10.1029/2000GL012471.

Davin, E. L., N. de Noblet-Ducoudré, and P. Friedlingstein (2007), Impact of land cover change on surface climate: Relevance of the radiative forcing concept, Geophys. Res. Lett., 34, L13702, doi:10.1029/2007GL029678.

Feddema, J. J., K. W. Oleson, G. B. Bonan, L. O. Mearns, L. E. Buja, G. A. Meehl, and W. M. Washington (2005), The importance of land-cover change in simulating future climates, Science, 310, 1674-1678, doi:10.1126/science. 1118160 .

Findell, K. L., T. R. Knutson, and P. C. D. Milly (2006), Weak simulated extratropical responses to complete tropical deforestation, J. Clim., 19, 2835-2850, doi:10.1175/JCLI3737.1.

Findell, K. L., E. Shevliakova, P. C. D. Milly, and R. J. Stouffer (2007), Modeled impact of anthropogenic land cover change on climate, J. Clim., 20, 3621-3634, doi:10.1175/JCLI4185.1.

Findell, K. L., A. J. Pitman, M. H. England, and P. Pegion (2009), Regional and global impacts of land cover change and sea surface temperature anomalies, J. Clim., doi:10.1175/2008JCLI2580.1, in press.

Forster, P., et al. (2007), Changes in atmospheric constituents and in radiative forcing, in Climate Change 2007: The Physical Science Basis. Contribution of Working Group I to the Fourth Assessment Report of the Intergovernmental Panel on Climate Change, edited by S. Solomon et al., pp. 129-234, Cambridge Univ. Press, Cambridge, U. K.

Gedney, N., and P. J. Valdes (2000), The effect of Amazonian deforestation on the Northern Hemisphere circulation and climate, Geophys. Res. Lett., 27, 3053-3056, doi:10.1029/2000GL011794.

Goldewijk, K. K. (2001), Estimating global land use change over the past 300 years: The HYDE database, Global Biogeochem. Cycles, 15(2), 417-433, doi:10.1029/1999GB001232.

Koster, R. D., et al. (2004), Regions of strong coupling between soil moisture and precipitation, Science, 305, 1138-1140, doi:10.1126/ science. 1100217.

Henderson-Sellers, A., R. E. Dickinson, T. B. Durbidge, P. J. Kennedy, K. McGuffie, and A. J. Pitman (1993), Tropical deforestation: Modelling local to regional-scale climate change, J. Geophys. Res., 98, 7289-7315, doi:10.1029/92JD02830.

Pitman, A. J. (2003), The evolution of, and revolution in, land surface schemes designed for climate models, Int. J. Climatol., 23, 479-510, doi:10.1002/joc.893.

Ramankutty, N., and J. A. Foley (1999), Estimating historical changes in global land cover: Croplands from 1700 to 1992, Global Biogeochem. Cycles, 13(4), 997-1027, doi:10.1029/1999GB900046. 
Seneviratne, S. I., D. Lüthi, M. Litschi, and C. Schär (2006), Land-atmosphere coupling and climate change in Europe, Nature, 443, 205-209, doi:10.1038/ nature 05095 .

Werth, D., and R. Avissar (2002), The local and global effects of Amazon deforestation, J. Geophys. Res., 107(D20), 8087, doi:10.1029/ 2001JD000717.

Zwiers, F. W., and H. von Storch (1995), Taking serial correlation into account in tests of the mean, J. Clim., 8, 336-351, doi:10.1175/1520-0442 (1995) $008<0336$ :TSCIAI $>2.0 . \mathrm{CO} ; 2$.

G. B. Bonan and P. J. Lawrence, National Center for Atmospheric Research, P.O. Box 3000, Boulder, CO 80307, USA. (bonan@ucar.edu; lawrence@ucar.edu)

V. Brovkin, M. Claussen, V. Gayler, and C. H. Reick, Max Planck Institute for Meteorology, Bundesstrasse 53, D-20146 Hamburg, Germany. (victor.brovkin@zmaw.de; martin.claussen@zmaw.de; veronika.gayler@ zmaw.de; christian.reick@zmaw.de)

F. T. Cruz and A. J. Pitman, Climate Change Research Centre, University of New South Wales, Sydney, NSW 2052, Australia. (faye.cruz@gmail. com; a.pitman@unsw.edu.au)
E. L. Davin and S. I. Seneviratne, Institute for Atmospheric and Climate Science, ETH Zürich, Universitätstrasse 16, CH-8092 Zürich, Switzerland. (edouard.davin@env.ethz.ch; sonia.seneviratne@env.ethz.ch)

N. de Noblet-Ducoudré, Laboratoire des Sciences du Climat et de l'Environnement, UVSQ, CEA, CNRS, Orme des Merisiers, Bât. 712, point Courrier 132, F-91191 Gif-sur-Yvette CEDEX, France. (nathalie.denoblet@1sce.ipsl.fr)

C. Delire and A. Voldoire, Groupe d'étude de l'Atmosphère Météorologique, Météo-France, CNRS, 42 Avenue G Coriolis, F-31057 Toulouse CEDEX, France. (christine.delire@meteo.fr; aurore.voldoire@meteo.fr)

L. Ganzeveld, Department of Environmental Sciences, Wageningen University and Research Centre, Droevendaalsesteeg 4, NL-6708 PB Wageningen, Netherlands. (laurens.ganzeveld@wur.nl)

C. Müller, Potsdam Institute for Climate Impact Research, Telegrafenberg A62, D-14471 Potsdam, Germany. (christoph.mueller@pik-potsdam.de)

B. J. Strengers, Netherlands Environmental Assessment Agency, P.O. Box 303, NL-3720 AH, Bilthoven, Netherlands. (bart.strengers@pbl.nl)

B. J. J. M. van den Hurk, Netherlands Royal Meteorological Institute, PO Box 201, NL-3730 AE De Bilt, Netherlands. (hurkvd@knmi.nl)

M. K. van der Molen, Faculty of Earth and Life Sciences, VU University Amsterdam, Boelelaan 1085, NL-1081 HV Amsterdam, Netherlands. (michiel.van.der.molen@falw.vu.nl) 